\title{
Ketoacidosis due to Starvation
}

\author{
Nalan Metin Aksu (D), Zehra Akcora (D), Bugra Ilhan (D), Ozgur Bayar (D), Meltem Akkas \\ Department of Emergency Medicine, Hacettepe University School of Medicine, Ankara, Turkey
}

Cite this article as: Metin Aksu N, Akcora Z, Ilhan B, Bayar O, Akkas M. Ketoacidosis due to Starvation. Eurasian J Emerg Med. 2018; 17: 39-40.

\begin{abstract}
Poor dietary intake, prolonged fasting, malnutrition, alcoholism, and protein-based diets may induce ketoacidosis without diabetes mellitus. This is called "starvation ketoacidosis." Here we present the case of a patient diagnosed with starvation ketoacidosis. A 38-year-old female was admitted to our emergency department because of chest and back pain. Electrocardiography and chest X-ray showed no abnormalities. On taking her past medical history, we learned that she had been diagnosed with anorexia nervosa. Anion gap metabolic acidosis with ketone bodies in urine was detected. A diagnosis of starvation ketoacidosis was considered for the patient, and she was treated with dextrose solution for $15 \mathrm{~h}$, and improved acidosis was observed. To the best of our knowledge, there are few case reports on starvation ketoacidosis. Emergency physicians should be aware of the complications of starvation and should immediately start the appropriate treatment.
\end{abstract}

Keywords: Starvation ketoacidosis, high anion gap, emergency department

\section{Introduction}

Ketoacidosis is a metabolic state wherein ketone bodies increase with decreasing serum bicarbonate level and $\mathrm{pH}$. Ketosis may occur during starvation because of poor carbohydrate intake, which leads to lipolysis and ketogenesis (1). Here the brain and other tissues use ketone bodies as an alternative energy source instead of glucose. Although ketoacidosis may be frequently seen as diabetic ketoacidosis in association with type I diabetes mellitus, poor dietry intake, prolonged fasting, malnutrition, gastric banding disorders, alcoholism, therapeutic ketogenic diets (used for the treatment of epileptic seizures, Alzheimer's disease, Parkinson's disease, and amyotrophic lateral sclerozis), Atkins diet, and last decade's famous Dukan diet may induce ketoacidosis without diabetes mellitus (2-8). This is known as starvation ketoacidosis. Here, we present the case of a 38-year-old female with anorexia nervosa who was diagnosed with starvation ketoacidosis.

\section{Case Presentation}

A 38-year-old female was admitted to our emergency department because of chest and back pain. Her initial vital signs were normal. Electrocardiography (ECG) and chest X-ray showed no abnormalities. Serum myoglobin, CK-MB, and troponin I levels were within reference ranges. Because of her chest pain and shortness of breath, we ordered her arterial blood gas (ABG) analysis. ABG values were as follows: $\mathrm{pH}: 7.26, \mathrm{pO}_{2}: 96 \mathrm{mmHg}, \mathrm{pCO}_{2}: 24 \mathrm{mmHg}, \mathrm{HCO}_{3}: 10.8 \mathrm{mMol} / \mathrm{L}$, and lactate: 1.1. $\mathrm{mMol} / \mathrm{L}$ Her serum electrolyte levels including $\mathrm{Na}$

ORCID IDs of the authors: N.M.A. 0000-0003-2256-5187; Z.A. 0000-0051-5296-0220; B.I. 0000-0002-3255-2964; O.B. 0000-0003-2307-8882.

Correspondence to: Nalan Metin Aksu e-mail: nametaksu@yahoo.com.tr 
Table 1. Arterial blood gas, serum elctrolytes, and glucose values

\begin{tabular}{|l|c|c|}
\hline & At admission & After treatment \\
\hline $\mathrm{pH}$ & 7.21 & 7.33 \\
\hline $\mathrm{pCO}_{2}(\mathrm{mmHg})$ & 31.3 & 37.9 \\
\hline $\mathrm{HCO}_{3}(\mathrm{mmol} / \mathrm{L})$ & 12 & 20 \\
\hline $\mathrm{Na}^{+}(\mathrm{mEq} / \mathrm{L})$ & 137 & 135 \\
\hline $\mathrm{K}^{+}(\mathrm{mEq} / \mathrm{L})$ & 4.13 & 3.3 \\
\hline $\mathrm{Cl}^{-}(\mathrm{mEq} / \mathrm{L})$ & 108 & 112 \\
\hline Anion $\mathrm{gap}$ & 17 & 3 \\
\hline Glucose $(\mathrm{mg} / \mathrm{dL})$ & 62 & 103 \\
\hline
\end{tabular}

(137 mEq/L) and $\mathrm{Cl}(108 \mathrm{mEq} / \mathrm{L})$ as well as blood urea nitrogen and creatinine levels were normal. We investigated the reason for her anion gap metabolic acidosis. She had no diabetes mellitus and her glucose was $99 \mathrm{mg} / \mathrm{dL}$, and there was no lactate level elevation. There was no history of alcohol intake. Her urine test showed 4 (+) ketone bodies. On taking a detailed past medical history, we learned that she had been diagnosed with anorexia nervosa. Her family stated that she had not eaten anything for several days. Therefore, we suspected that the patient was in a state of ketoacidosis due to starvation. We consultated the patient to the nephrology department and then started treatment with $50 \mathrm{cc} / \mathrm{h}$ of $10 \%$ dextrose. We measured blood glucose levels every $2 \mathrm{~h}$ and serum electrolytes, $A B G$, and urine tests every $4 \mathrm{~h}$. After $15 \mathrm{~h}$ of treatment initiation, ABG values became normal, and there were no ketone bodies in her urine test (Table 1). Her complaints also ceased. We discharged the patient with the recommendation to follow up with psychiatry and nephrology.

\section{Discussion}

To the best of our knowledge, few case reports have been published on starvation ketoacidosis. Blood glucose level decreases with decrease in insulin and increase in glucagon during starvation (3). Decreased insulin level leads to increased activity of lipase. Lipase breaks downs triglyceride into free fatty acid chains (FFAs). These FFAs oxidize ketone bodies in the liver. A literature search revealed case reports on ketocidosis due to several reasons, the most common reason being diabetes mellitus. However, our patient had no history of diabetes and nor was she pregnant. She also had no intractable vomiting. She had also no history of alcohol or medicines that may lead to metabolic acidosis. Sepsis may lead to ketoacidosis without diabetes, but her clinical condition did not indicate sepsis (9). Further, she had no history of gastric banding operation. In these conditions, ketoacidosis may be explained by the lack of insulin and poor metabolic function. Ketoacidosis may be life-threatening during lactation. There was a case report on a nondiabetic woman who fasted during lactation (10). There were case reports of ketoacidosis due to low carbohyrate-high protein diets such as Atkins and Dukan $(7,8)$. We found another case report of severe diabetic ketoacidosis with anorexia nervosa and type I diabetes (11). We investigated the reason for the ketoacidosis in our patient by detailing her past medical history. We finally concluded the diagnosis to be starvation ketoacidosis. The goal of the treatment is to reduce gluconeogenesis. This can be achieved by administering combined dextrose and insulin infusion or dextrose infusion alone (3). Insulin can switch off ketogenesis and provide a more rapid recovery. But during insulin infusion, glucose levels have to be closely observed to avoid hypoglycemia. The recommended treatment time varies from $24 \mathrm{~h}$ to $72 \mathrm{~h}$. Occasionally, acidosis state recovers in $24 \mathrm{~h}$ following the treatment $(3,8)$. Our patient recovered after $15 \mathrm{~h}$ of her treatment.

\section{Conclusison}

Starvation ketoacidosis may present as high anion gap metabolic acidosis and may be life-threatening. Because of this reason, emergency physicians should be aware of the complications of starvation and also immediately start the approtiate treatment.

Informed Consent: We didn't use the patient's photograph or identification informations in this case report so we didn't obtained the informed consent form.

Peer-review: Externally peer-reviewed.

Author Contributions: Concept - N.M.A.; Design - N.M.A., M.A.; Supervision - N.M.A., M.A.; Resources - Z.A., B.I., O.B.; Materials - O.B.; Data Collection and/ or Processing - B.O., Z.A., B.I.; Analysis and/or Interpretation - N.M.A., M.A., B.I.; Literature Search - N.M.A., M.A., B.I.; Writing Manuscript - N.M.A., M.A.; Critical Review - N.M.A., M.A., Z.A., B.I., B.O.

Conflict of Interest: No conflict of interest was declared by the authors.

Financial Disclosure: The authors declared that this study has received no financial support.

\section{References}

1. Cartwright MM, Hajja W, Al-Khatib S, Hazeghazam M, Sreedhar D, Na Li $E$, et al. Toxigenic and metabolic causes of ketosis and ketoacidotic syndromes. Crit Care Clin. 2012; 28: 601-31.

2. Kitabchi AE, Umpierrez GE, Miles JM, Fisher JN. Hyperglycemic crises in adult patients with diabetes. Diabetes Care. 2009; 32: 1335-43.

3. Lulsegged A, Saeed E, Langford E, Duffield C, El-Hasani S, Pareek N. Starvation Ketoacidosis in a patient with gastric banding. Clin Med (Lond). 2011; 11: 73-5.

4. Wheless J. The history of the ketogenic diet. Epilepsia. 2008; 49: 3-5. [CrossRef]

5. Gasior M, Rogawski MQA, Hartman AL. Neuroprotective and disease modifying effects of the ketogenic diet. Behav Pharmacol. 2006; 17: 431-9.

6. Henderson ST. Ketone bodies as a therapeutic for Alzheimer's disease. Neurotherapeutics. 2008; 5: 470-80.

7. Chen TY, Smith W, Rosenstock JL, Lessnau KD. A life threatening complication of Atkins diet. Lancet. 2006; 367: 958.

8. Freeman FT, Willis B, Krywko DM. Acute intractable vomiting and severe Ketoacidosis secondary to the Dukan diet. J Emerg Med. 2014; 47: 10912.

9. Nakamura K, Inokuchi R, Doi K, Fukuda T, Tokunaga K, Nakajima S, et al. Septic Ketoacidosis. Intern Med. 2014; 53: 1071-3.

10. Geijer L, Elelund M. Ketoacidosis associated with low carbohydrate diet in a non-diabetic lactating woman: a case report. J Med Case Rep. 2015; 9: 224.

11. Espes D, Engström J, Reinius H, Carlsson P. Severe diabetic Ketoacidosis in combination with starvation and anoreia nervosa at onset type 1 diabetes: A case report. Ups J Med Sci. 2013; 118: 130-3. 